\title{
Acid and enzymatic extraction of collagen from Atlantic cod (Gadus Morhua) swim bladders envisaging health-related applications
}

\author{
Rita O. Sousa, Ana L. Alves, Duarte Nuno Carvalho, Eva Martins, Catarina \\ Oliveira, Tiago H. Silva \& Rui L. Reis
}

To cite this article: Rita O. Sousa, Ana L. Alves, Duarte Nuno Carvalho, Eva Martins, Catarina Oliveira, Tiago H. Silva \& Rui L. Reis (2019): Acid and enzymatic extraction of collagen from Atlantic cod (Gadus Morhua) swim bladders envisaging health-related applications, Journal of Biomaterials Science, Polymer Edition, DOI: 10.1080/09205063.2019.1669313

To link to this article: https://doi.org/10.1080/09205063.2019.1669313

Accepted author version posted online: 17

Sep 2019.

Published online: 27 Sep 2019.

Submit your article to this journal $\pi$

Llll Article views: 14

Q View related articles $\sqsubset$

View Crossmark data $\nearrow$ 


\title{
Acid and enzymatic extraction of collagen from Atlantic cod (Gadus Morhua) swim bladders envisaging health- related applications
}

\author{
Rita O. Sousa ${ }^{a, b}$ (D), Ana L. Alves ${ }^{a, b}$ (D), Duarte Nuno Carvalho ${ }^{a, b}$ (ID, Eva \\ Martins $^{a, b}$ (D), Catarina Oliveira ${ }^{a, b}$ (D), Tiago H. Silva ${ }^{a, b}$ (ID) and Rui L. Reis ${ }^{a, b, c}$ \\ a3B's Research Group, I3Bs - Research Institute on Biomaterials, Biodegradables and Biomimetics, \\ University of Minho, Headquarters of the European Institute of Excellence in Tissue Engineering and \\ Regenerative Medicine, Avepark - Parque de Ciência e Tecnologia, Guimarães, Portugal; ' ${ }^{\prime} I C V S / 3 B^{\prime}$ s - \\ PT Government Associate Laboratory, Guimarães, Portugal; 'The Discoveries Centre for Regenerative \\ and Precision Medicine, Headquarters at University of Minho, Guimarães, Portugal
}

\begin{abstract}
Atlantic cod is processed industrially for food purposes, with several by-products being directed to animal feed and other ends. Looking particularly into swim bladders, the extraction of collagen can be a valuable strategy for by-product valorization, explored in the present work for the first time. Collagen was extracted using acetic acid (ASCsb) and pepsin (PSCsb) with yields of $5.72 \%(\mathrm{w} / \mathrm{w})$ and $11.14 \%(w / w)$, respectively. SDS-PAGE profile showed that the extracts were compatible with type I collagen. FTIR, CD and XRD results suggest that the PSCsb structure underwent partial denaturation, with microDSC showing a band at $54{ }^{\circ} \mathrm{C}$ probably corresponding to a melting process, while ASCsb structure remained intact, with preserved triple helix and a denaturation temperature of $29.6^{\circ} \mathrm{C}$. Amino acid composition indicates that the total content of proline-like amino acids was 148/1000 residues for ASCsb and $141 / 1000$ residues for PSCsb, with a hydroxylation degree of about $37 \%$. The extracts exhibited a typical shear thinning behavior, interesting property regarding their further processing toward the development of biomaterials. In this regard, assessment of metabolic activity of human fibroblast cells cultured in the presence of collagen extracts with concentrations up to $3 \mathrm{mg} / \mathrm{mL}$ revealed the absence of cytotoxic behavior. Collagen extracts obtained from Atlantic cod swim bladders shown attractive properties regarding their use in cosmetic or biomedical applications.
\end{abstract}

\section{ARTICLE HISTORY}

Received 19 June 2019

Accepted 13 September 2019

\section{KEYWORDS}

Fish Collagen; extraction; swim bladders; Atlantic cod; marine biomaterials

\section{Introduction}

Atlantic cod (Gadus morhua) is one of the most important commercial fish species in Portugal [1], having a unique status in national culture, from its production to the

CONTACT Tiago H. Silva tiago.silva@i3bs.uminho.pt 3B's Research Group, I3Bs - Research Institute on Biomaterials, Biodegradables and Biomimetics, University of Minho, Headquarters of the European Institute of Excellence in Tissue Engineering and Regenerative Medicine; Avepark - Parque de Ciência e Tecnologia, Zona Industrial da Gandra, 4805-017 Barco - Guimarães, Portugal.

Color versions of one or more of the figures in the article can be found online at www.tandfonline.com/tbsp. 
Portuguese gastronomy. In the case of the cod processing industry, about $40 \%(\mathrm{w} / \mathrm{w})$ of raw-material resulted in by-products such as swim bladders, viscera, skin, bones and fins [2], which may represent a sustainable resource of interest to the economy of food supplements, feed and value-added compounds (biopolymers, enzymes, bioactive compounds) and from this to other with higher added-value. In fact, different ingredients, such as proteins, lipids, taurine, collagen, calcium, and phosphorous can be extracted from cod by-products [3], opening several biotechnological application possibilities.

The main part of the fish by-products resulting from the fisheries and food processing industries is still directed for fish silage, fishmeal and oil production, mainly used for animal feed [3,4]. Nevertheless, cod by-products have already been used, for example, for the extraction of collagen [5,6] and fish leather production from skin, the extraction of calcium phosphates such as hydroxyapatite from bones [7], the isolation of enzymes from liver, as well as other valuable compounds from viscera or muscle [4]. In this project, swim bladders were removed from salt-cured cod (Gadus morhua) and used to extract fish protein - collagen. The swim bladder or air bladder is an internal gas-filled organ that contributes to the ability of many bony fish (but not cartilaginous fish) to control their buoyancy, avoiding the waste of energy in swimming. Additionally, the swim bladder functions as a resonating chamber, to produce or receive sound and it is evolutionarily homologous to the lungs $[8,9]$. The swim bladder consists of three main layers: tunica externa, submucosa, and mucosa. The tunica externa is composed of a dense layer of connective tissue [9], being a potential source for the production of collagen.

Collagen is the main protein of connective tissue and the most abundant in vertebrate and invertebrate organisms [6,10-12]. It represents about $30 \%$ of total proteins, having a fundamentally structural role in connective tissue as skins, tendons, ligaments and bones, being the most prevalent component of the extracellular matrix (ECM) [13]. There are more than 20 collagens reported so far, differently distributed in animal tissues, being type I collagen the most studied in marine species [6]. Collagens of marine origin have gained more attention and importance because of their high extraction yield and availability, no risk of pathogen infection compared to land-based animals (cows, pigs, poultry, etc.) collagen, minor regulatory and ethical issues and no religious barriers $[12,14,15]$. Marine collagen from fish, sponges and jellyfish is increasingly used in various biomedical, cosmetics and pharmaceuticals applications [6,16,17]. As examples, collagen was studied to form hydrogels and porous scaffolds for tissue engineering and regeneration purpose [18-21], as a food supplement but also as an ingredient in cosmetics [5], with potential application by incorporation in formulations for creams and lotions. These strategies foster the establishment of highly profitable processes, which corresponds to a shift to a molecular level of utilization of by-products, where the biomolecules recovered would be applied outside the primary sector, with clear economic, environmental and biotechnological benefits [10].

The objective of this work was to address the extraction of collagen from Atlantic cod swim bladders, obtained as marine by-products from the processing of cod for food purposes using a treatment based in salting and drying. The extracted collagens were extensively characterized regarding their physical and chemical properties, as well as examining the rheology behavior and eventual cytotoxicity considering the future application in cosmetics and biomedical context. 


\section{Materials and methods}

\subsection{Materials}

Swim bladders from Atlantic cod (Gadus morhua) were removed after a salting processing step and kindly offered by a local industry, Soguima (Guimarães, Portugal). The swim bladders were transported to the laboratory and stored at $-20^{\circ} \mathrm{C}$ until further use. All reagents used were of analytical grade and used as received.

\subsection{Extraction of collagen}

The isolation of collagen from cod swim bladders was performed by an acid and pepsin extraction methodology, similar to the one commonly followed for fish skins, adapted from Kaewdang et al. [22] and $\mathrm{Lu}$ et al. [23]. The swim bladders were cleaned several times with distilled water, for removal of salt and muscle debris, and cut into small pieces to enhance the extraction. To remove non-collagenous proteins, the swim bladders were rinsed with $0.15 \mathrm{M} \mathrm{NaOH}(1: 10 \mathrm{w} / \mathrm{v})$ for 3 hours under stirring, changing the solution every 1 hour. The swim bladders were then washed several times with cold distilled water until neutrality and further defatted by immersion in $10 \%(\mathrm{v} / \mathrm{v}) 2$-propanol with a 1:10 (w/v) ratio for 24 hours under stirring. The resulting materials were further washed with abundant and cold distilled water and freezedried for subsequent collagen extraction. Pre-treated swim bladders samples were placed in $0.5 \mathrm{M}$ acetic acid solution $(1: 10 \mathrm{w} / \mathrm{v})$ for 3 days under stirring, followed by centrifugation at $20,000 \mathrm{~g}$ during $30 \mathrm{~min}$ at $4{ }^{\circ} \mathrm{C}$. The supernatant, rich in acid soluble collagen (ASCsb) was collected and the remaining biomass were re-extracted with $10 \%$ pepsin added to $0.5 \mathrm{M}$ acetic acid to obtain pepsin soluble collagen (PSCsb), also followed by centrifugation at $20,000 \mathrm{~g}$ during $30 \mathrm{~min}$ at $4{ }^{\circ} \mathrm{C}$. To precipitate the collagens, both supernatants were salted out by adding $\mathrm{NaCl}$ to a final concentration of $2.6 \mathrm{M}$ in $0.05 \mathrm{M}$ Tris- $\mathrm{HCl}(\mathrm{pH}$ 7.5) and left overnight. The precipitate was removed by centrifugation at $20,000 \mathrm{~g}$ during $30 \mathrm{~min}$ at $4{ }^{\circ} \mathrm{C}$ and re-suspended in $0.5 \mathrm{M}$ of acetic acid. The solution was dialyzed first against $0.1 \mathrm{M}$ acetic acid for 2 days, then against $0.02 \mathrm{M}$ acetic acid for 2 days, and finally against distilled water until $\mathrm{pH}$ 7. All the previous procedures were performed at $4{ }^{\circ} \mathrm{C}$ to avoid collagen denaturation. The solution was freeze-dried and stored at room temperature until further use.

\subsection{Characterization of the extracted collagen}

\subsubsection{Extraction yield}

The extraction yield was determined as the ratio between the final product (weight of freeze-dried collagen extract) and the initial product (wet weight of by-products biomass) (Equation (1)).

$$
\text { Yield of collagen }(\text { wet })(\%)=\frac{\text { Weight of collagen }(\mathrm{g})}{\text { Weight of wet swim bladders }(\mathrm{g})} \times
$$




\subsubsection{Fourier-Transform infrared (FTIR) spectroscopy}

The samples ASCs, PSCs (acid soluble collagen and pepsin soluble collagen from cod skin) ASCsb and PSCsb were respectively mixed and analysed with potassium bromide $(\mathrm{KBr})$ pellets. The infrared spectra of collagen structures were obtained with a Shimadzu- IR Prestige 21 spectrometer in the spectral region of $4000-800 \mathrm{~cm}^{-1}$ for collagen with resolution of $2 \mathrm{~cm}^{-1}$, as an average of 32 scans.

\subsubsection{Amino acid analysis}

The amino acid content of ASCs, PSCs, ASCsb and PSCsb were determined by quantitative analysis using a Biochrome 30 apparatus (Biochrome Ltd., Cambridge, U.K.). Briefly, the samples were completely hydrolysed and separated by an ion Exchange column. After post-column derivatization by ninhydrin, the samples were analysed at two wavelengths: 440 and $570 \mathrm{~nm}$. An internal standard of norleucine was used to determine the concentration of amino acids in the sample.

\subsubsection{Micro differential scanning calorimetry}

Micro-DSC measurements were carried out with a high-sensitivity SETARAM Micro DSC III microcalorimeter, using $700 \mu \mathrm{L}$ samples in stainless steel cells to determine the denaturation temperature. Nitrogen was used as purge gas to avoid humidity condensation on the circulating coils of the microcalorimeter. All collagen samples were dissolved at $5 \mathrm{mg} / \mathrm{mL}$ in $0.5 \mathrm{M}$ acetic acid, under stirring, at $4{ }^{\circ} \mathrm{C}$. DSC scans of $5 \mathrm{mg} /$ $\mathrm{mL}$ of collagen (Coll) from calf skin Bornstein and Traub type I (Sigma) was used as reference material. The mass of sample was weighed directly in the measure cell and solution of $0.5 \mathrm{M}$ acetic acid was also placed in the reference cell during DSC scans. Measurements were made at $1 \mathrm{~K} \mathrm{~min}^{-1}$ scan rate in the temperature range of $5-80{ }^{\circ} \mathrm{C}$.

\subsubsection{Circular dichroism analysis}

Circular dichroism (CD) measurements of the ASCsb and PSCsb were performed using a Jasco Model J1500 spectropolarimeter (Jasco, U.K.) using a quartz cylindrical cuvette (Hellma, Germany) with a path length of $2 \mathrm{~mm}$, at $4^{\circ} \mathrm{C}$. The cuvette was filled with $600 \mu \mathrm{l}$ of sample $(0.1 \mathrm{mg} / \mathrm{mL})$ for each measurement. CD spectra were obtained by continuous wavelength scans (average of three scans) from 180 to $240 \mathrm{~nm}$ at a scan-rate of $50 \mathrm{~nm} / \mathrm{min}$.

\subsubsection{X-ray diffraction (XRD)}

XRD measurements were obtained using a conventional Bragg-Brentano diffractometer (Bruker D8 Advance DaVinci, Germany) equipped with $\mathrm{CuK} \alpha$ radiation, produced at $40 \mathrm{kV}$ and $40 \mathrm{~mA}$. Data sets were collected in the $2 \theta$ range of $5-30^{\circ}$ with a step size of $0.02^{\circ}$ and $1 \mathrm{~s}$ for each step. The average crystallite size was estimated with the Bragg equation (Equation (2)):

$$
\text { d }(\AA)=\lambda / 2 \sin \theta(\lambda \operatorname{Cuk} \alpha 1=1.5406)
$$




\subsubsection{SDS-PAGE analysis}

Dodecyl sulfate-polyacrylamide gel electrophoresis (SDS-PAGE) was prepared using reagents from Sigma SDS-PAGE reagents and casted on a Biorad Mini Protean II System. Freeze-dried collagen was dissolved in $0.5 \mathrm{M}$ acetic acid $(10 \mathrm{mg} / \mathrm{mL})$ under stirring. The solutions were then mixed 1:1 (v/v) with loading buffer and heated $10 \mathrm{~min}$ at $95^{\circ} \mathrm{C}$ to completely denature the proteins. The type I collagen from bovine skin (used as reference) and the samples ASCs, PSCs, ASCsb and PSCsb (20 $\mu \mathrm{L})$ were loaded onto SDS-PAGE gel, as well as $4 \mu \mathrm{L}$ of protein marker. Both separating and stacking gels were run at $90 \mathrm{~V}$. After running, the gels were stained in a Coomassie (0.500 g Coomassie Brilliant Blue G-250 (Biorad), $500 \mathrm{~mL}$ methanol, $100 \mathrm{~mL}$ acetic acid and $400 \mathrm{~mL}$ deionized water) staining solution for $30 \mathrm{~min}$. Excess stain was removed with Destain I $(80 \mathrm{~mL}$ methanol, $14 \mathrm{~mL}$ acetic acid and $156 \mathrm{~mL}$ deionized water) for $30 \mathrm{~min}$ and Destain II $(12.5 \mathrm{~mL}$ methanol, $17.5 \mathrm{~mL}$ acetic acid and $220 \mathrm{~mL}$ deionized water) overnight, under stirring.

\subsubsection{Gel permeation chromatography - size exclusion chromatography}

The studied collagen samples (ASCsb and PSCsb) were analysed by gel permeation chromatography with a refractometer, right angle laser-light scattering and a viscosity detectors (TDA 305 - Viskotec, Malvern, UK). Novema Precolumn $(10 \mu \mathrm{m}$, $8 \times 50 \mathrm{~mm})$, Novema $30 \AA \quad(10 \mu \mathrm{m}, 8 \times 300 \mathrm{~mm})$, Novema $1000 \AA \quad(10 \mu \mathrm{m}$, $8 \times 300 \mathrm{~mm})$ and Novema $1000 \AA(10 \mu \mathrm{m}, 8 \times 300 \mathrm{~mm})$ were used for the polymers separation. The system was kept at $30^{\circ} \mathrm{C}$ and $0.15 \mathrm{M} \mathrm{NH} 4 \mathrm{OAc} / 0.2 \mathrm{M} \mathrm{AcOH}$ buffer $(\mathrm{pH} 4.5)$ was used as eluent, at rate of $1 \mathrm{~mL} / \mathrm{min}$. Pullulan $47 \mathrm{kDa}$ and polydispersity index (PDI) 1.07 (PSS standard services) was used to obtain a multidetector calibration (used to obtain the absolute $\mathrm{Mw}$ ). The $\mathrm{dn} / \mathrm{dc}$ was established as 0.186 after a literature search $[24,25]$.

\subsubsection{Rheology}

Rheological analyses were performed using a Kinexus pro + rheometer (Malvern Instruments, UK), using the acquisition software rSpace. The measuring system used in these experiments is composed by a stainless steel cone ( $40 \mathrm{~mm}$ of diameter and $4^{\circ}$ ) and plate geometries. The surface geometry was covered with dodecane to prevent water loss. Rotational experiments were performed in order to obtain shear viscosity as a function of the shear rate, from $0.1^{-1}$ to $1000 \mathrm{~s}^{-1}$, at $25^{\circ} \mathrm{C}$. All plots are obtained by the average of at least 3 experiments. These experiments were conducted with two collagen samples (ASCsb and PSCsb) at $3 \%(\mathrm{w} / \mathrm{v})$ in $0.02 \mathrm{M}$ acetic acid.

\subsubsection{Cytotoxicity}

Cell Expansion - Human fibroblast cell line (MRC-5) was cultured in D-MEM low glucose medium (Sigma-Aldrich) supplemented with 10\% FBS (Alfagene) and Pen/ Strep (100 U/100 g mL - 1; Life Technologies). Fibroblasts were used at passages 1722. Cells were incubated at $37^{\circ} \mathrm{C}$ in a humidified $5 \% \mathrm{CO} 2$ atmosphere. Media was exchanged every 2-3 days until cells reached a $90 \%$ confluence. 
Cell Culture - Cells were harvested and 15,000 cells were cultured in 24 well-plates. The cells were left to adhere for $4 \mathrm{~h}$ and, after that, collagen extracts were added to adherent cells. Extracts were dissolved in the culture medium at different concentrations: $0.25,0.5,1,2,3,4$, and $5 \mathrm{mg} \mathrm{mL}-1$. For all the assays a positive control was performed (no biological extract in the culture medium). Each experimental condition was tested in triplicate and two independent assays were performed.

Cell Viability - The metabolic activity of cells, cultured with different extracts' concentrations and time points, was determined by the MTS assay (CellTiter 96 AQueous One Solution, Promega). Basically, the quantity of formazan product is directly proportional to the number of living cells in culture. At days 1, 2, and 3, the culture medium was removed and the testing conditions were rinsed with sterile Phosphate-Buffered Saline (PBS). A mixture of culture medium (without FBS and phenol red) and MTS reagent (5:1 ratio) was added to each well and left to incubate for $3 \mathrm{~h}$, at $37^{\circ} \mathrm{C}$, in a humidified $5 \% \mathrm{CO} 2$ atmosphere. Thereafter, the absorbance of the MTS reaction medium from each sample was read in triplicate at $490 \mathrm{~nm}$ in a microplate reader (Synergy HT, Bio-TEK). All experiments were performed in triplicate.

\subsection{Statistical analysis}

All tests were performed in triplicate and the data are presented as mean \pm standard deviation (SD). Statistical analysis was performed using GraphPad Prism Software. Differences between the several conditions of the cellular assays were analysed using nonparametric test (Kruskal-Wallis test), as the respective samples did not fit with the assumptions of normality (Shapiro-Wilk); $\mathrm{p}<0.05$ was considered significant.

\section{Results and discussion}

\subsection{Extraction of collagen}

Acid-soluble collagen (ASCsb) and pepsin-soluble collagen (PSCsb) were extracted from cod swim bladders with a yield of $5.72 \%$ and $11.14 \%$, respectively, in respect to the wet weight of raw-material. The results indicated an increase in collagen extraction yield in pepsin digestion because the telopeptide region was cleaved by this enzyme, facilitating the removal of the proteins from the remaining matrix. This is in agreement with previous studies for other fish species and by-products (like skin). Kaewdang et al. (2014) reported that ASC and PSC (acid soluble collagen and pepsin soluble collagen) from yellowfin tuna swim bladders were extracted with a yield of $1.07 \%$ and $12.10 \%$, respectively. The differences in yields can be attributed to the different collagen structures in marine fish and the varying crosslinking of collagen fibrils in different by-products [12].

\subsection{SDS-PAGE analysis}

In order to access structural information, purity and breakdowns of collagen protein upon extraction, sodium dodecyl sulfate - polyacrylamide gel electrophoresis (SDS- 


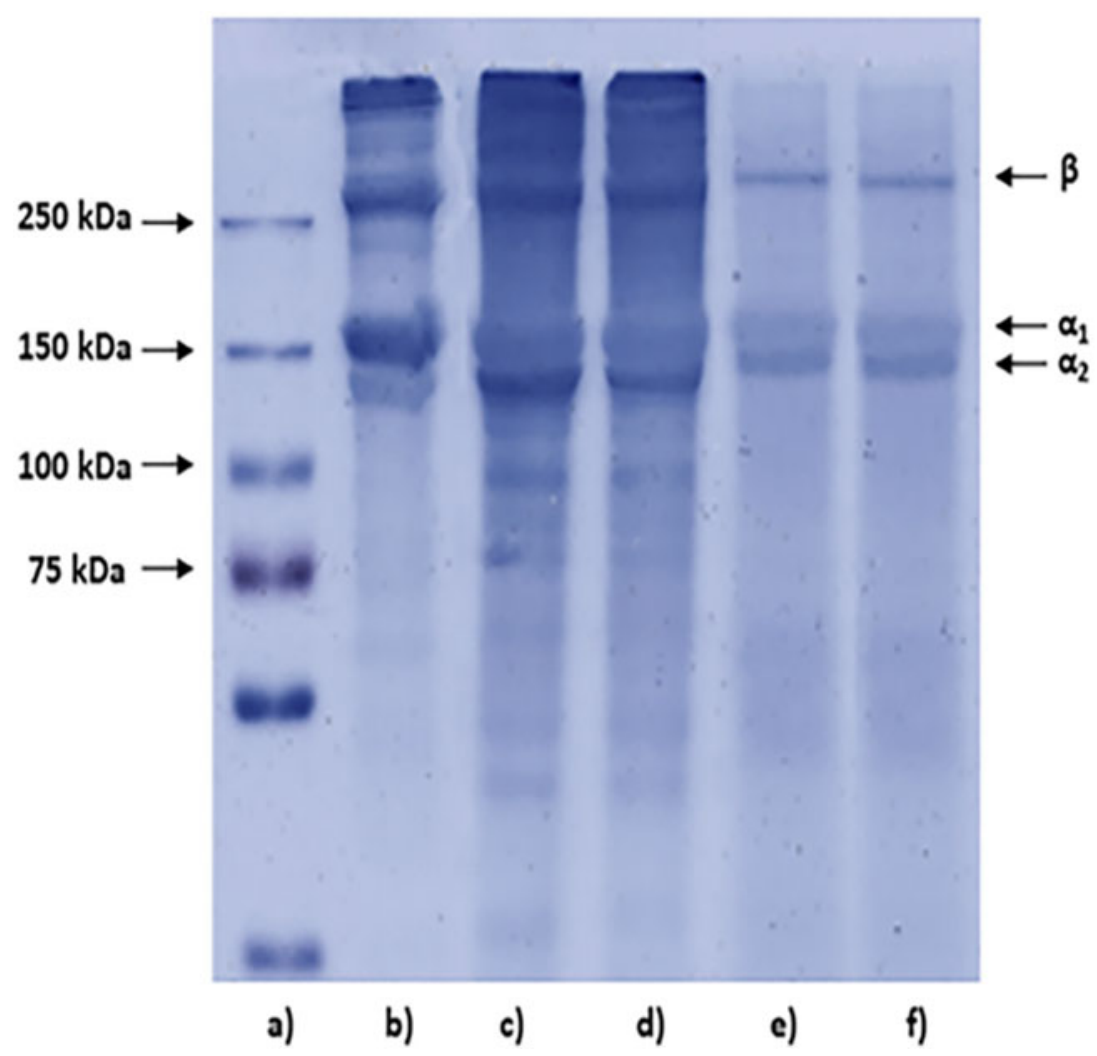

Figure 1. Electrophoresis analysis of cod skin and swim bladder collagen. a) protein marker; b) type I collagen from bovine skin; c) ASCs; d) ASCsb; e) PSCs and f) PSCsb.

PAGE) was used to separate proteins fragments according to their size. The collagens extracted from cod swim bladders were submitted to this analysis, together with collagen from cod skin and type I collagen from bovine skin as reference. Figure 1 displays the illustrative results, with the profiles of the several collagen extracts exhibiting the characteristic bands of type I collagen which is considered the gold standard in biomedical industries and tissue engineering approaches. The SDS-PAGE bands profiles of the swim bladder collagens (ASCsb and PSCsb) were quite similar to the equivalent collagens obtained from the skin of the same fish, as shown in Figure 1, demonstrating the feasibility of using swim bladders for the isolation of collagen, as reported for other fish species [12,22,23]. Moreover, the similarity of those profiles with the one exhibited by type I collagen obtained from bovine skin, namely the presence of two distinct $\alpha$-chains ( $\alpha 1$ and $\alpha 2$ ), with molecular weight of about $150 \mathrm{kDa}$, with $\alpha 1$ much more intense than $\alpha 2$ (theoretically, the double), as well as dimers - $\beta$ chain - at about $250 \mathrm{kDa}$, is compatible with a classification of swim bladder collagens as type I $[6,13]$. Nevertheless, based on the electrophoretic patterns of collagens extracted from cod swim bladders, there are differences between ASCsb and PSCsb, suggesting that the crosslinks of collagens were more abundant in ASCsb than in PSCsb. It may be due that some $\beta$ and $\gamma$ (trimer) components were cleaved after digestion with pepsin [12]. 


\subsection{Chemical characterization of ASCsb and PSCsb}

The collagen extracted from cod swim bladders were characterized by FTIR, with the representative spectra being shown in Figure 2. The spectra shown very similar profiles, suggesting that the extracts present similar structures and chemical compositions, with the characteristic peaks of Amide A, Amide B, Amide I, Amide II and Amide III being clearly visible. These findings are similar with other found in literature for other marine species [12,22,26-28], as well as with collagens extracted from cod skin, also displayed in Figure 2 as reference. The N-H stretching vibration typical of intermolecular hydrogen bonding, commonly observed in a range between 3000 $3500 \mathrm{~cm}^{-1}$, is relative to the Amide A band and was here observed at $3400 \mathrm{~cm}^{-1}$. The absorption characteristic of amide $\mathrm{B}$, relative to the asymmetrical and symmetrical stretch of $\mathrm{CH} 2$ is found at $2935 \mathrm{~cm}^{-1}$ and $2926 \mathrm{~cm}^{-1}$ for ASCsb and PSCsb,

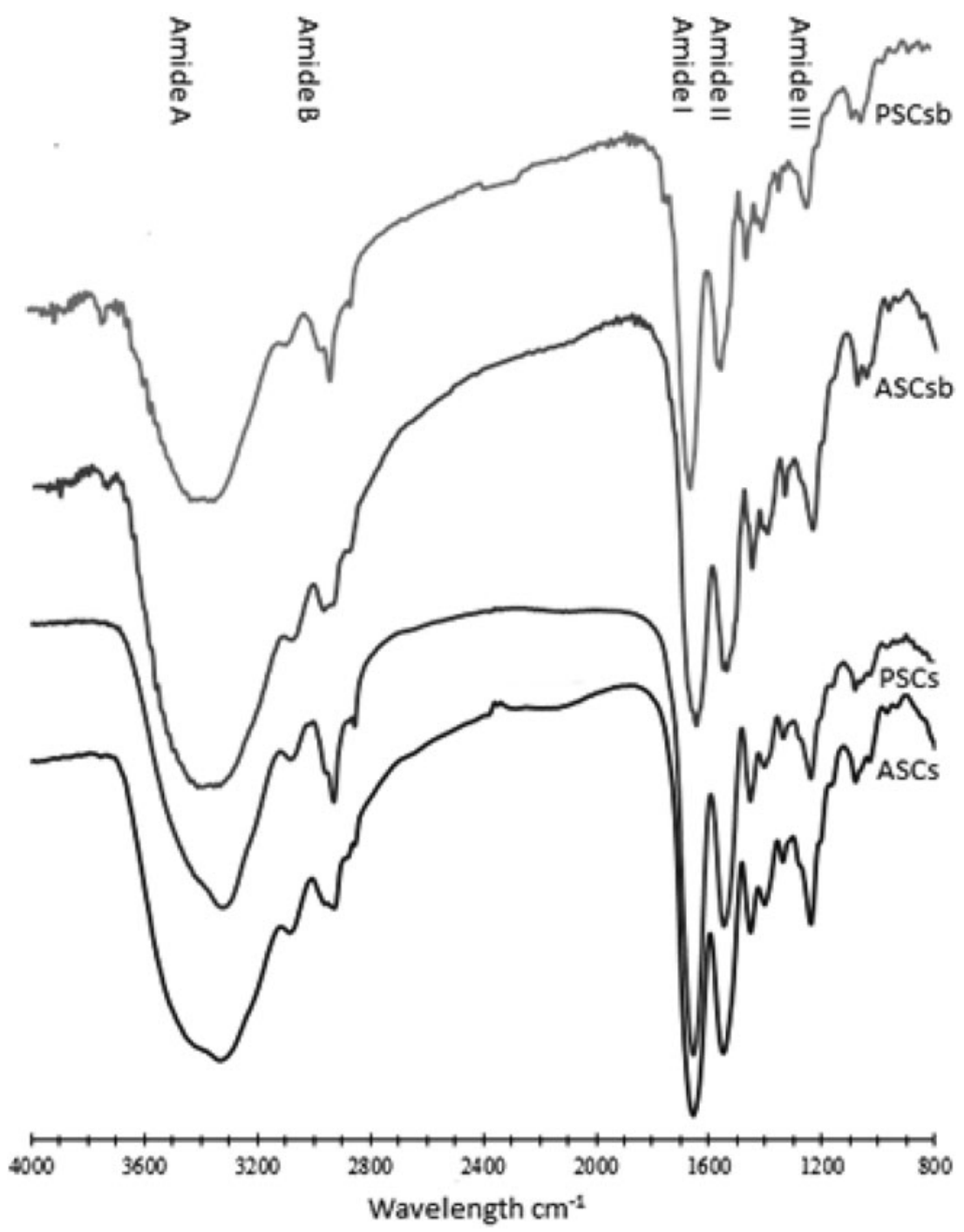

Figure 2. FTIR spectra of ASCs, PSCs, ASCsb and PSCsb from cod. 
Table 1. Amino acid composition of ASCs, PSCs, ASCsb and PSCsb from cod.

\begin{tabular}{|c|c|c|c|c|}
\hline \multirow[b]{2}{*}{ Amino acid } & ASCs & PSCs & ASCsb & PSCsb \\
\hline & \multicolumn{4}{|c|}{ Residues per 1000 total amino acid residues } \\
\hline Asp & 49 & 51 & 50 & 51 \\
\hline Thr & 22 & 23 & 21 & 22 \\
\hline Ser & 68 & 69 & 66 & 72 \\
\hline Glu & 74 & 70 & 73 & 71 \\
\hline Gly & 348 & 347 & 337 & 338 \\
\hline Ala & 121 & 127 & 122 & 126 \\
\hline Cys & 3 & 3 & 3 & 3 \\
\hline Val & 15 & 15 & 13 & 14 \\
\hline Met & 22 & 18 & 19 & 20 \\
\hline lle & 8 & 8 & 8 & 8 \\
\hline Leu & 21 & 18 & 21 & 21 \\
\hline Nleu & 13 & 16 & 14 & 16 \\
\hline Tyr & 3 & 3 & 4 & 4 \\
\hline Phe & 16 & 15 & 18 & 17 \\
\hline OhLys & 1 & 1 & 6 & 6 \\
\hline His & 7 & 5 & 6 & 6 \\
\hline Lys & 27 & 26 & 27 & 25 \\
\hline Arg & 45 & 38 & 46 & 41 \\
\hline OhPro & 50 & 53 & 54 & 53 \\
\hline Pro & 89 & 95 & 94 & 88 \\
\hline Total & 1000 & 1000 & 1000 & 1000 \\
\hline
\end{tabular}

respectively, while amide I peak that is characteristic of the stretching vibrations of $\mathrm{C}=\mathrm{O}$ groups of proteins occurred at $1651 \mathrm{~cm}^{-1}$ and $1649 \mathrm{~cm}^{-1}$, respectively. The absorption band characteristic of amide II was very similar for ASCsb and PSCsb, arising at $1543 \mathrm{~cm}^{-1}$ correspondent to $\mathrm{NH}$ bending vibration couplet with $\mathrm{CN}$ stretching; $1454 \mathrm{~cm}^{-1}$, attributed to $\mathrm{CH} 2$ bending; and $1398 \mathrm{~cm}^{-1} / 1396 \mathrm{~cm}^{-1}$, deriving from COO-symmetrical stretching, respectively. The band of amide III occurred at $1337 \mathrm{~cm}^{-1} / 1336 \mathrm{~cm}^{-1}$, correspondent to $\mathrm{NH}$ bending associated with $\mathrm{CN}$ stretching; and $1236 \mathrm{~cm}^{-1} / 1238 \mathrm{~cm}^{-1}$, relative to C-O stretching, respectively.

The amino acid composition was analysed in order to understand the quantitative composition of the extracted collagens. The results of this analysis (in n/1000 residues) for ASCsb and PSCsb are presented in Table 1 and compared with ASCs and PSCs, as reference. The amino acid content of collagen extract from cod swim bladders are similar to collagen extract from cod skin and the reported for other species $[11,12,22,29]$. The extracts are rich in glycine (Gly), alanine (Ala), proline (Pro) and hydroxypoline (OhPro), as characteristic of collagen. Glycine is the major amino acid in all extracts, being about $1 / 3$ of amino acid residues, namely 337 for ASCsb and 338 for PSCsb per 1000 residues, followed by alanine with 122 and 126 residues, respectively. This is consistent with the fact that glycine occurs regularly at every third residue throughout most of the collagen molecules, with some exceptions like the first 14 amino acids from N-terminus and the first 10 from C-terminus [30], the telopeptides. The total proline contents (Pro and OhPro) of ASCsb and PSCsb are 148 and 141 residues/1000 residues, respectively. Proline and hydroxyproline are important for the structural integrity of collagen, being correlated to species (lower in fish than mammalian) and their living temperature [30]. In addition to the total proline contents, the hydroxylation degree is also relevant, namely for the structural integrity and thermal stability of collagens [11,12,22], being determined as $36,49 \%$ 


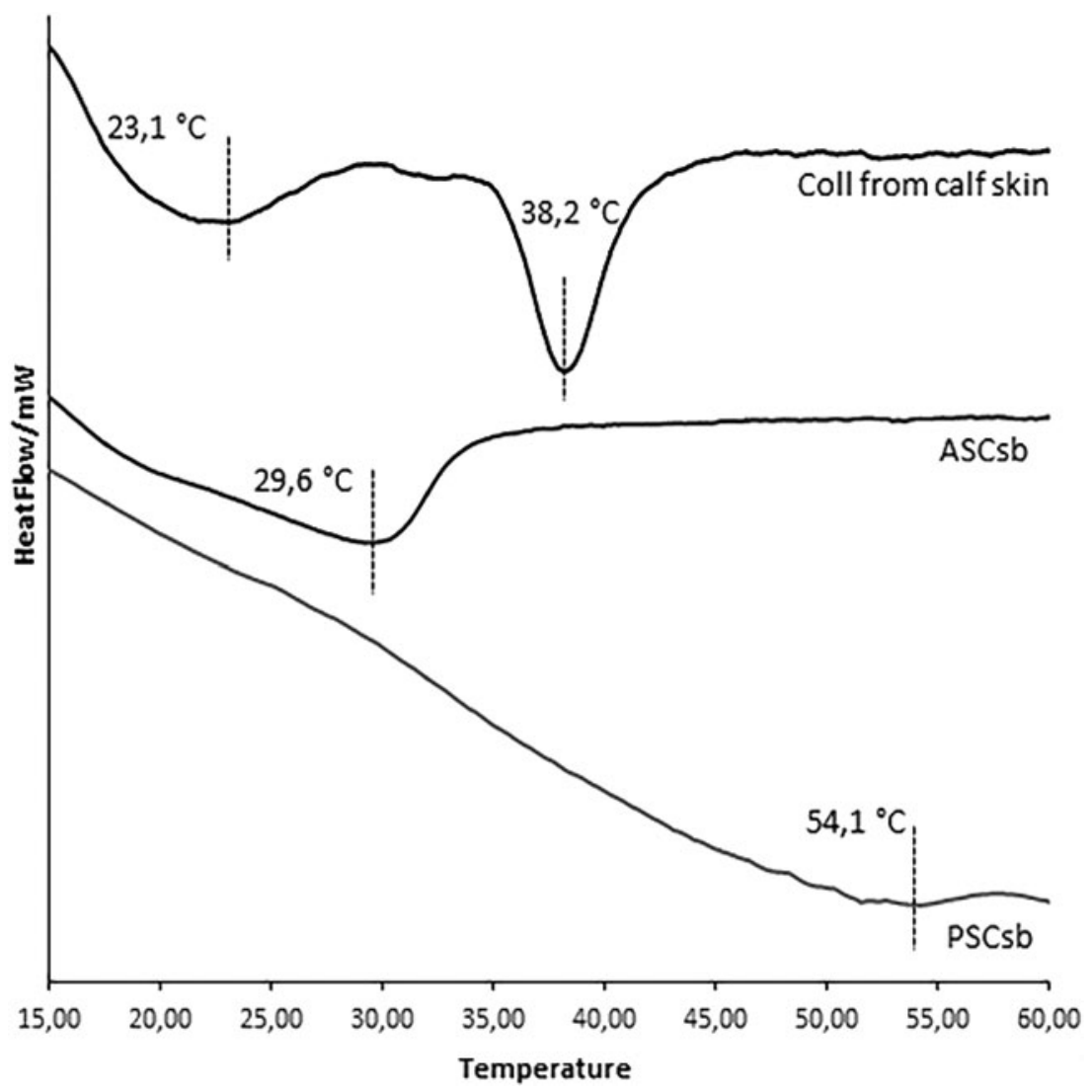

Figure 3. Micro-DSC spectra of ASCsb, PSCsb and Coll from calf skin (used as reference).

and $37,59 \%$ for ASCsb and PSCsb, respectively, similar to the observed for ocellate puffer fish [31].

In order to verify the process of heat-induced denaturation, micro-DSC measurements were carried out. Figure 3 shows the DSC curves describing the heat flow to the collagen samples, ASCsb and PSCsb, as well as Coll from calf skin used as reference, when submitted to heating under inert atmosphere. The ASCsb and PSCsb DSC curves displayed only one endothermal peak, being different from the two obtained for coll from calf skin, used as reference as this is one of the principal sources of medical grade collagen [32]: one at $23.1^{\circ} \mathrm{C}$ originated from the breaking of hydrogen bonds among collagen molecules [33] and another at $38.2^{\circ} \mathrm{C}$ referring to denaturation process, which is directly related to: the number of amino acids like hydroxyproline [6,33], fish habitat [11], physiological temperature of the fish [34], hydration level of collagen [35] and type of extraction. For the acid extracted collagen, an evident peak was observed at $29.6{ }^{\circ} \mathrm{C}$, corresponding to the denaturation temperature (Td), thus thermally less stable than the one observed for calf skin collagen, but within the higher values described by others for fish collagens, commonly associated with fresh water fish. Surprisingly, the thermogram for PSCsb does not exhibit a well-defined peak attributable to denaturation process, but only a wide band with a maximum at about $54.1^{\circ} \mathrm{C}$, which may be due to a melt-like process, not visible for 


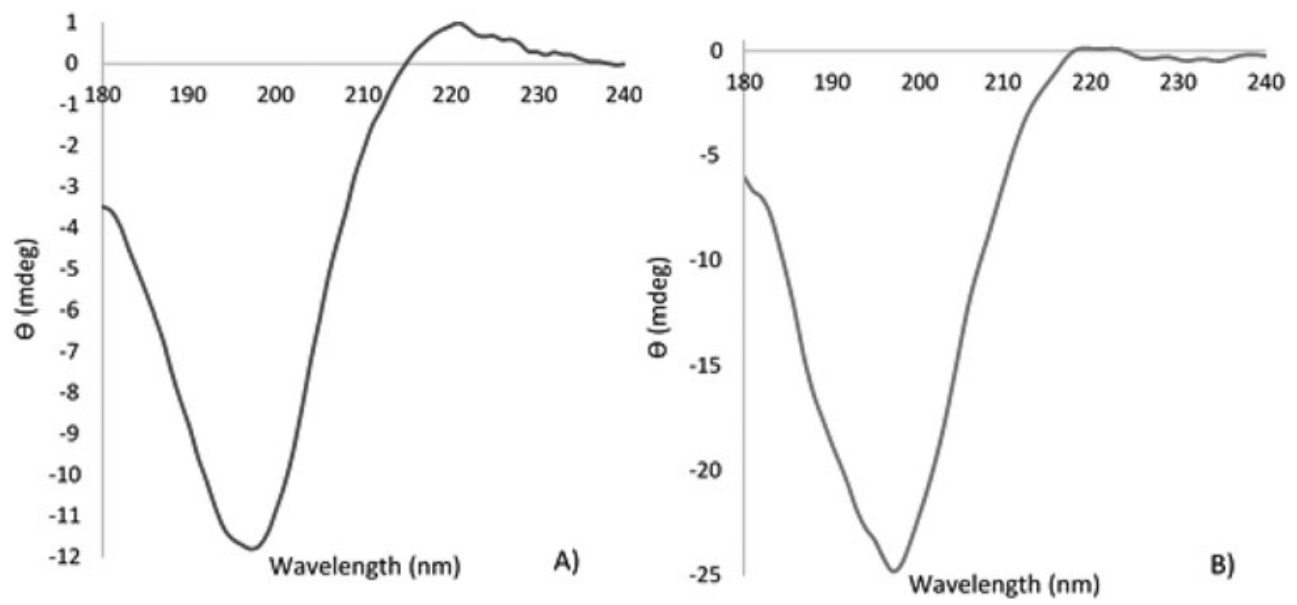

Figure 4. CD spectra of A) ASCsb and B) PSCsb from cod, measured at $4{ }^{\circ} \mathrm{C}$.

the other analysed samples. This may be due to the fact that the PSCsb already has some degree of denaturation and less amount of preserved peptide alpha chains, which may be leading to a different structural organization and/or hydration level.

The secondary structure of ASCsb and PSCsb was determined by Circular dichroism (CD) and X-ray diffraction spectroscopy (XRD). CD was performed to confirm that the extracts were in the native state, being an effective technique to identify whether the triple helical structure was intact. ASCsb CD spectrum shown in Figure 4 depicts a positive peak at $221 \mathrm{~nm}$ (maximum positive cotton effect), characteristic of the presence of triple helix, and a negative peak at $198 \mathrm{~nm}$ (maximum negative cotton effect), with a crossover point (zero rotation) at approximately $215 \mathrm{~nm}$, compatible with the observed by other authors [36,37]. However, the spectrum of PSCsb shows only a very small positive peak at $219 \mathrm{~nm}$ and a well-defined negative peak at $197 \mathrm{~nm}$, which is indicative of a partially denaturation of the protein and consecutive loss of triple helix, which supports the discussion made above for the thermal characterization of the samples.

In a complementary analysis, the XRD spectra of both collagen samples were also obtained, as this technique is able to detect patterns as the ones that would be defined by the presence of preserved protein secondary structure. For both ASCsb and PSCsb spectra (Figure 5) one can identify two peaks, characteristics of collagen [36,38], with corresponding diffraction angles $(2 \theta)$ of $7.64^{\circ}$ and $20.07^{\circ}$ for ASCsb, and $7.74^{\circ}$ and $20.11^{\circ}$ for PSCsb. The first sharp peak is associated with the triple helical structure of collagen [36] and from the Bragg equation one can determine the corresponding $\mathrm{d}$ value: $11.56 \AA$ and $11.41 \AA$ for ASCsb and PSCsb, respectively, indicating the distance between the molecular chains within the triple helix. From the value of the second broad peak angle it is possible to calculate the distance between skeletons, determined as $4.41 \AA$ and $4.42 \AA$ for ASCsb and PSCsb, respectively. These results are closed to that observed for grass carp and Nile tilapia [36,39], corresponding to the diameter of a collagen molecule with a triple helix structure and a single left-handed propeller chain. The two peaks are much more evident in the ASCsb spectrum, reflecting that ASCsb is in its native and non-denatured conformations, while PSCsb should have 


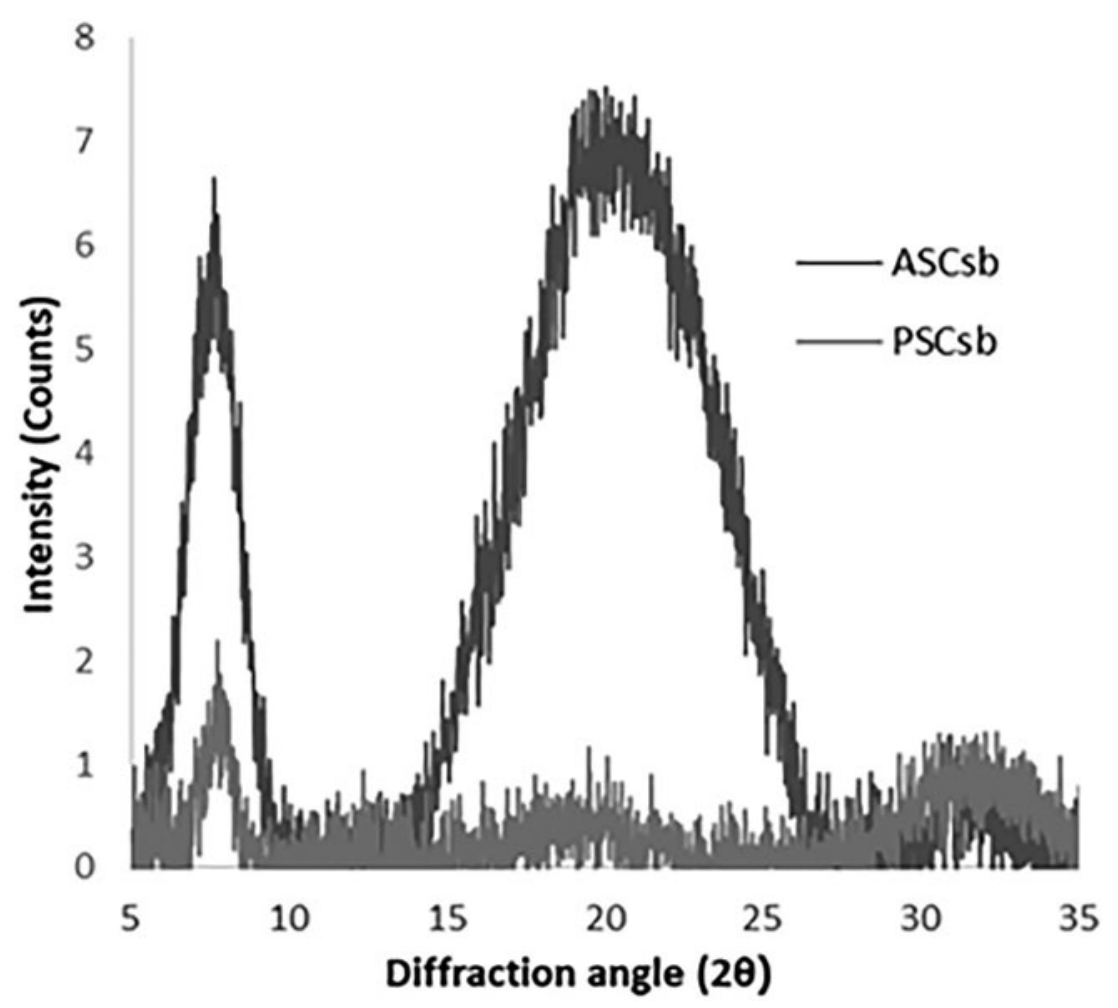

Figure 5. XRD spectra of ASCsb and PSCsb from cod.

experienced some degree of denaturation, in agreement with the observed previously on the $\mathrm{CD}$ and thermal analyses.

\subsection{Molecular weight determination by GPC-SEC}

A polymeric solution contains at least hundreds of polymer chains. These chains are not homogenous in nature. They probably differ in several physicochemical properties, the molecular weight being one of them [40]. The GPC-RALS method allows the determination of the Number Average Molecular Weight (Mn) and Weight Average Molecular Weight (Mw), as well as the polydispersity (Mw/Mn) [41]. The Mn can be defined as Total mass of material divided by the total number of molecules, meanwhile the Mw can be described as the total mass of material multiplied by the molecules mass. The molecular weight of a substance, particularly a polymer, is a key chemical characteristic that can dramatically influence the material mechanical performance, particularly the viscosity and rheological behavior [42]. The results show that the higher molecular masses correspond to ASCsb (Table 2). This is confirmed by the elution times showed in the chromatograms, where high molecular weight molecules will elute first. These chromatograms are wide, indicating broad molar mass distribution. This is in concordance with the PDI values obtained. Although not manifested in its PDI, PSCsb has probably a subtle tendency to form aggregates. This particularity can be deduced from the form of its RI curve, which presents a lump in 
Table 2. Molecular weights and polydispersities of the studied collagens. The average values of the obtained Number Average Molecular Weights (Mn), Weight Average Molecular Weights (Mw) and polydispersities $(\mathrm{Mw} / \mathrm{Mn})$ are displayed, together with the corresponding standard deviations.

\begin{tabular}{lrrr}
\hline Collagen & Mn $(\mathrm{kDa})$ & $\mathrm{Mw}(\mathrm{kDa})$ & PDI \\
\hline ACSsb & $128.8 \pm 6.4$ & $182.9 \pm 7.9$ & $1.420 \pm 0.010$ \\
PSCsb & $23.6 \pm 2.7$ & $28.7 \pm 1.7$ & $1.227 \pm 0.150$ \\
\hline
\end{tabular}

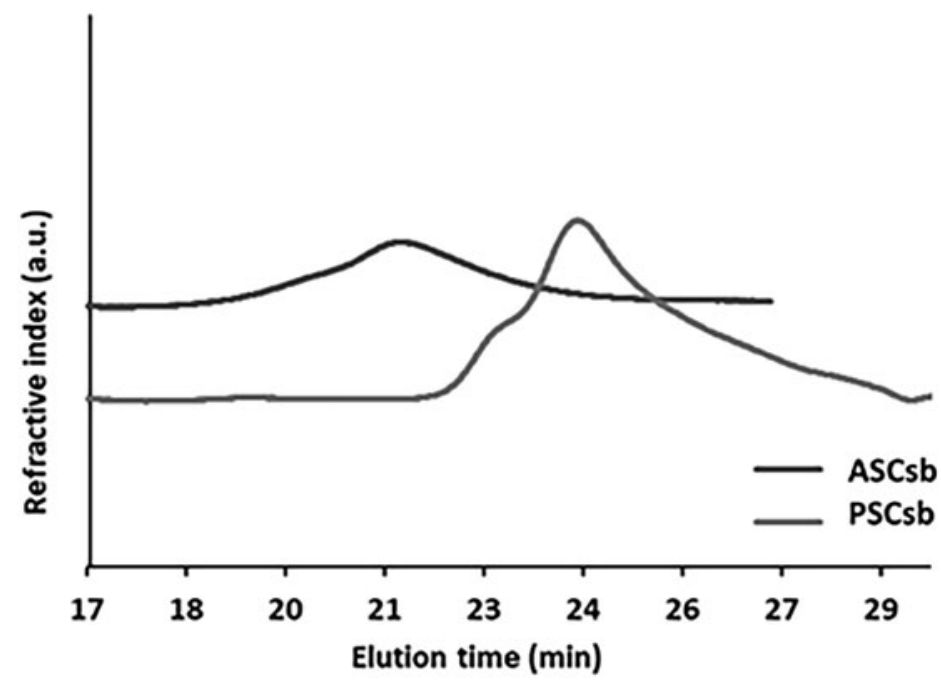

Figure 6. Gel permeation chromatograms of the studied collagens. The obtained refractive indexes (RIs) are expressed at the corresponding elution times.

its left hillside (Figure 6). The ASCsb result is in agreement with the SDS-PAGE profile but the same is not observed in the result of PSCsb, possibly due to the conformation of the molecule.

\subsection{Rheological behavior of collagen extracts}

The viscosity behavior of a 3 wt. \% aqueous solution of the extract obtained as a function of shear rate was evaluated, not only regarding the characterization of the materials but also toward application development, with the obtained results described in Figure 7.

Flow behavior was described by the fitting of the experimental data (shear stressshear rate) with the power law model (Equation (3)): $\tau=k \dot{\gamma} \eta$, where $\tau$ is the shear stress $(\mathrm{Pa}), \dot{\gamma}$ is the shear rate $\left(\mathrm{s}^{-1}\right), \mathrm{k}$ is the consistency coefficient (Pa.sn) and $\eta$ is the flow behavior index (Ma et al., 2014). ASCsb and PSCsb presented a flow behavior index $\eta=0.33 \pm 0.01$ and $\eta=0.61 \pm 0.16$, respectively, characteristic of nonNewtonian fluids (for Newtonian liquid, $\mathrm{n}=1$, pseudo plastic fluid $\mathrm{n}<1$ and swelling plastic fluid $n>1$ ). Moreover, ASCsb and PSCsb samples exhibits a typical shear thinning behavior for different shear rates, characterized by a decrease in the viscosity with increasing shear rate and a linear relationship between the shear rate and shear stress [26]. This shear-thinning (pseudo plastic) behavior, also present in hyaluronic 


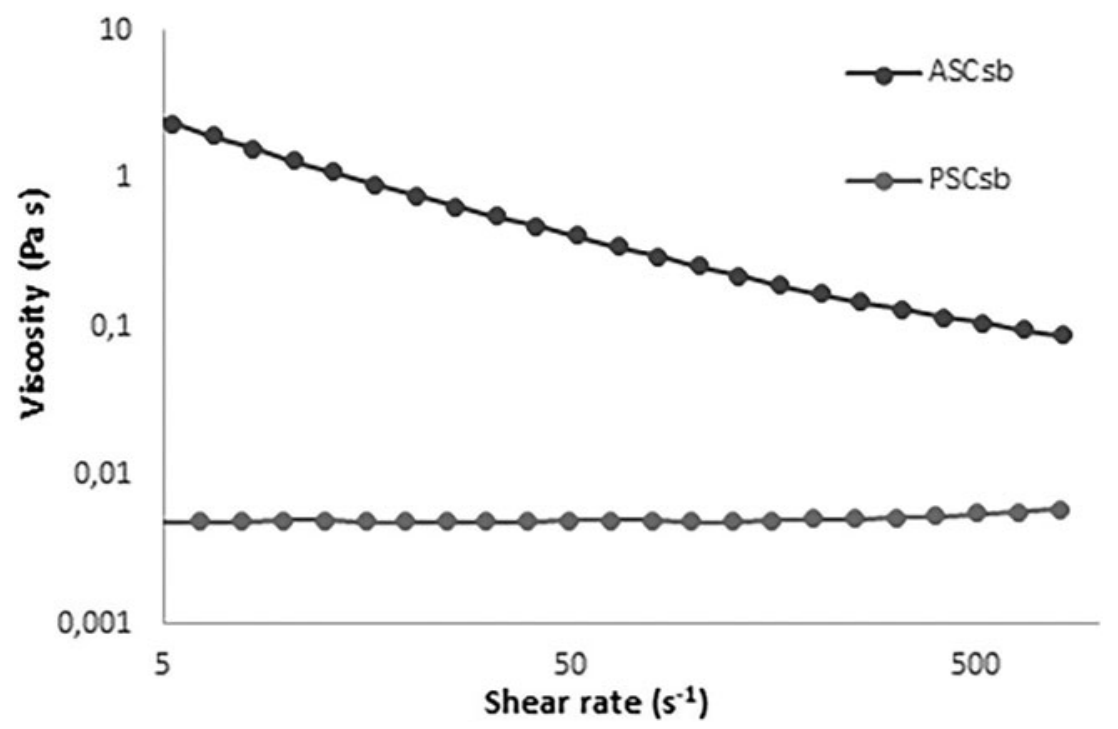

Figure 7. Viscosity curve of ASCsb and PSCsb (3wt \%) extracted from cod.

acid aqueous solutions [43,44], reveals to be an interesting rheological property regarding its further processing, namely on the production of different types of biomaterials, including injectable systems, envisaging biomedical application, namely on tissue engineering and regeneration, but also as component in cosmetic formulations.

\subsection{Cytotoxicity}

In the present study, the eventual cytotoxic effect of collagen extracts over MRC-5 human fibroblasts was evaluated by assessing their metabolic activity after culturing the cells in the presence of varying concentrations of extracts $(0.25-5 \mathrm{mg} / \mathrm{mL})$ for 1 , 2 , and 3 days (Figure $8 \mathrm{~A}$ and B), by using the MTS assay. No significant variation in the metabolic activity of MCR-5 cells was observed after 1 day of incubation, which is in accordance with previously published results demonstrating that fish collagen is not cytotoxic after 1 day of incubation at concentrations below $1 \%(10 \mathrm{mg} / \mathrm{mL})$ [32]. Nevertheless, a slight cytotoxicity was observed with the higher concentrations of ASCsb extract ( $5 \mathrm{mg} / \mathrm{mL}$, day 2 and 3) and PSCsb extract (4 and $5 \mathrm{mg} / \mathrm{mL}$, day 3 ). Despite the differences observed for the higher concentrations in respect to the control, maybe caused by experimental artifact, cell viability is still quite high. Therefore, these results are quite promising when envisaging the use of these collagens isolated from Atlantic cod swim bladder in biomedical context, namely on the development of biomaterials (hydrogel, membrane or other).

\section{Conclusions}

A feasible methodology for the extraction of ASCsb and PSCsb from Atlantic cod swim bladders was established, with the respective products being compatible with 

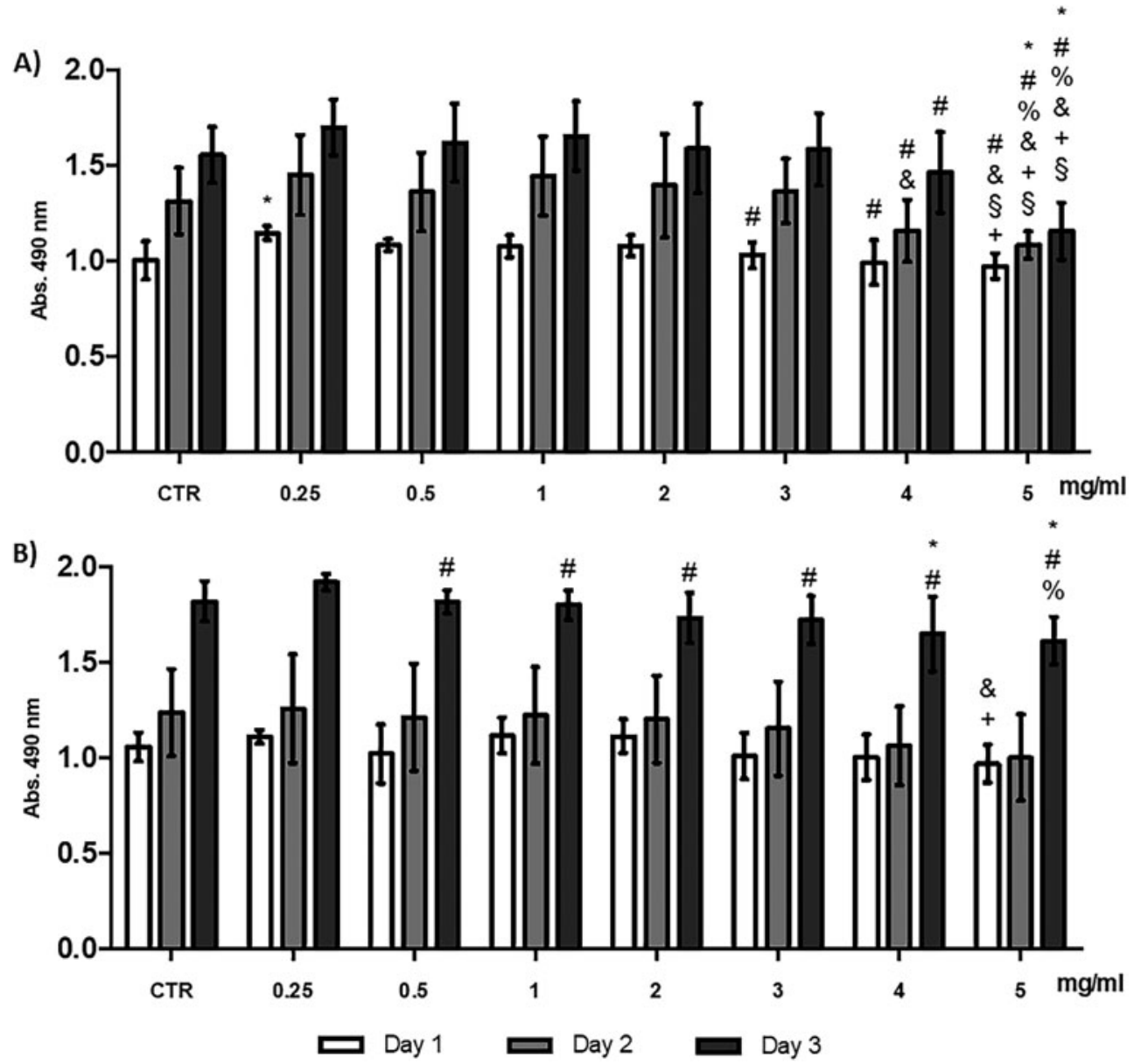

Figure 8. Metabolic activity of human fibroblast cell line (MRC-5) cultured in the presence of $A$ ) ASCsb and B) PSCsb, at different concentrations, during 1, 2 and 3 days. Data were considered statistically different if $\mathrm{p}<0.05$. * indicates significant differences when compared to CTR; \#, when compared to $0.25 \mathrm{mg} / \mathrm{mL}$; $\%$, when compared to $0.5 \mathrm{mg} / \mathrm{mL}$; \&, when compared to $1 \mathrm{mg} / \mathrm{mL}$; , when compared to $2 \mathrm{mg} / \mathrm{mL} ; \S$, when compared to $3 \mathrm{mg} / \mathrm{mL}$.

type I collagens, according with the SDS-PAGE profile. The results of the FTIR, XRD and $\mathrm{CD}$ analyses indicated that the acid extraction rendered collagen with preserved triple helix structure, while extraction with pepsin - although capable to increase the collagen production yield - had an adverse effect over the triple-helical structure, resulting in partial denaturation of collagen. The collagen extracts solutions obtained presented a physical viscous appearance, with interesting rheological and cytotoxicity behavior envisaging their biomedical application, namely to be processed further as biomaterials for tissue engineering, given the shear thinning behavior and neglected effect over human fibroblasts viability. Swim bladders can thus be considered as a good alternative source for the production of collagens, in a biotechnological strategy enhancing the value of fish by-products. 


\section{Acknowledgements}

The authors also thank to Dr. Sandra Pina (3B's Research Group) for assistance on XRD measurements, to Dr. Rita Lopez-Cebral (3B's Research Group) for assistance on SEC measurements and to Dr. Manuela Pintado, Dr. Raquel Madureira and Joana Costa (Faculty of Biotechnology, Portuguese Catholic University, Porto, Portugal) for the use and assistance on microDSC analysis. Soguima (Guimarães, Portugal) is also acknowledged for the kind offer of Atlantic cod swim bladders.

\section{Funding}

The authors would like to acknowledge to European Union for the financial support under the scope of European Regional Development Fund (ERDF) through the Structured Project NORTE-01-0145-FEDER-000021 (Norte2020) and under the scope of the European Union Seventh Framework Programme (FP7/2007-2013) through grant agreement ERC-2012-ADG 20120216-321266 (ERC Advanced Grant ComplexiTE). The Portuguese Foundation for Science and Technology is also acknowledged for the $\mathrm{PhD}$ grant of A.L.A under Doctoral Programme Do* Mar (PD/BD/127995/2016), as well as Norte2020 Regional Programme for the PhD grant of C. O. (Norte-08-5369-000037).

\section{ORCID}

Rita O. Sousa (D) http://orcid.org/0000-0003-3943-9996

Ana L. Alves (D) http://orcid.org/0000-0002-1552-4056

Duarte Nuno Carvalho (D) http://orcid.org/0000-0003-3115-0012

Eva Martins (D) http://orcid.org/0000-0003-1498-1893

Catarina Oliveira (D) http://orcid.org/0000-0002-4014-6472

Tiago H. Silva (D) http://orcid.org/0000-0001-8520-603X

Rui L. Reis (D) http://orcid.org/0000-0002-4295-6129

\section{References}

[1] Ottera H. FAO Cultured Aquatic Species Information Programme - Gadus Morhua. Cult. Aquat. Species Inf. Program. FAO Fish. Aquac. Dep. 2004

[2] ALIF-Associação da Indústria Alimentar pelo Frio. Necessidades da indústria relativamente à valorização de subprodutos de pescado. IPMA. 2014;

[3] Meldstad F. Hydrolysis of Marine Cod (Gadus Morhua) Head. 2015;1-77.

[4] Penven A, Perez-Galvez R, Bergé JP. By-products from Fish Processing: Focus on French Industry. Chap. 1. In: Perez Galvez R, Berge JP Editors. Utilization of fish waste. Boca Raton, FL: CRC Press; 2013. p. 1-25.

[5] Alves A, Marques A, Martins E, et al. Cosmetic potential of marine fish skin collagen. Cosmetics. 2017;4(4):39.

[6] Silva TH, Moreira-Silva J, Marques ALP, et al. Marine origin collagens and its potential applications. Mar Drugs. 2014;12(12):5881-5901.

[7] Piccirillo C, Rocha C, Tobaldi DM, et al. A hydroxyapatite-Fe2O3based material of natural origin as an active sunscreen filter. J Mater Chem B. 2014;2(36): 5999-6009.

[8] Chapman CJ, Hawkins AD. A field study of hearing in the cod, Gadus morhua L. J Comp Physiol. 1973;85(2):147-167.

[9] Fänge R. Gas exchange in fish swim bladder. In: Reviews of physiology, biochemistry and pharmacology. Vol. 97. Berlin, Heidelberg: Springer; 1983. p. 111-158. 
[10] Ferraro V, Anton M, Santé-Lhoutellier V. The "sisters" $\alpha$-helices of collagen, elastin and keratin recovered from animal by-products: functionality, bioactivity and trends of application. Trends Food Sci Technol. 2016;51:65-75.

[11] Tylingo R, Mania S. Isolation and characterization of acid soluble collagen from the skin of African catfish (Clarias gariepinus), Salmon (Salmo salar) and Baltic cod (Gadus morhua). J Biotechnol Biomater. 2016; 6: 234

[12] Wu X, Cai L, Cao A, et al. Comparative study on acid-soluble and pepsin-soluble collagens from skin and swim bladder of grass carp (Ctenopharyngodon idella). J Sci Food Agric. 2016;96(3):815-821.

[13] Shoulders MD, Raines RT. Collagen structure and stability. Annu Rev Biochem. 2009; 78:929-958.

[14] Berillis P. Marine collagen: extraction and applications In: Saxena M, editor. Research trends in biochemistry, molecular biology and microbiology. Dover, DE: SM Group open access eBooks; 2015. p. 1-13.

[15] Silvipriya KS, Kumar KK, Bhat AR, et al. Collagen. J App Pharm Sci. 2015;5:123-127.

[16] Ehrlich H. Marine Collagens. Biol Mater Mar Orig Vertebr. 2015; 321-341.

[17] Silva TH, Alves A, Ferreira BM, et al. Materials of marine origin: a review on polymers and ceramics of biomedical interest. Int Mater Rev. 2012;57(5):276-306.

[18] Coelho RCG, Marques ALP, Oliveira SM, et al. Extraction and characterization of collagen from Antarctic and Sub-Antarctic squid and its potential application in hybrid scaffolds for tissue engineering. Mater Sci Eng C. 2017;78:787-795.

[19] Fernandes-Silva S, Moreira-Silva J, Silva TH, et al. Porous hydrogels from shark skin collagen crosslinked under dense carbon dioxide atmosphere. Macromol Biosci. 2013; 13(11):1621-1631.

[20] Mredha MTI, Zhang X, Nonoyama T, et al. Swim bladder collagen forms hydrogel with macroscopic superstructure by diffusion induced fast gelation. J Mater Chem B. 2015; 3(39):7658-7666.

[21] Skopinska-Wisniewska J, Kuderko J, Bajek A, et al. Collagen/elastin hydrogels crosslinked by squaric acid. Mater Sci Eng C. 2016;60:100-108.

[22] Kaewdang O, Benjakul S, Kaewmanee T, et al. Characteristics of collagens from the swim bladders of yellowfin tuna (Thunnus albacares). Food Chem. 2014;155:264-270.

[23] Lu XJ, Chen J, Chen MZ, et al. Hydrolysates of swim bladder collagen from miiuy croaker, Miichthys miiuy, enhances learning and memory in mice. Curr Top Nutraceutical Res. 2010;8:149-156.

[24] Brokaw JL, Doillon CJ, Hahn RA, et al. Turbidimetric and morphological studies of type I collagen fibre self assembly in vitro and the influence of fibronectin. Int J Biol Macromol. 1985;7(3):135-140.

[25] Zhu J, Kaufman LJ. Collagen i self-assembly: revealing the developing structures that generate turbidity. Biophys J. 2014;106(8):1822-1831.

[26] Silva JC, Barros AA, Aroso IM, et al. Extraction of collagen/gelatin from the marine demosponge chondrosia reniformis (Nardo, 1847) using water acidified with carbon dioxide - process optimization. Ind Eng Chem Res. 2016;55(25):6922-6930.

[27] Barros AA, Aroso IM, Silva TH, et al. Water and carbon dioxide: green solvents for the extraction of collagen/gelatin from marine sponges. ACS Sustainable Chem Eng. 2015; 3(2):254-260.

[28] Muyonga JH, Cole CGB, Duodu KG. Characterisation of acid soluble collagen from skins of young and adult Nile perch (Lates niloticus). Food Chem. 2004;85(1):81-89.

[29] Zelechowska E, Sadowska M, Turk M. Isolation and some properties of collagen from the backbone of Baltic cod (Gadus morhua). Food Hydrocoll. 2010;24:325-329.

[30] Foegeding EA, Lanier TC, Hultin HO. Caracteristics of edible muscle tissues. Chap. 15 In: Owen Fennema R, editor. Food chemistry. Vol. 3. New York, NY: Marcel Dekker Inc.; 1996. p. 879-942.

[31] Nagai T, Araki Y, Suzuki N. Collagen of the skin of ocellate puffer fish (Takifugu rubripes). Food Chem. 2002;78(2):173-177. 
[32] Kuzan A, Smulczyńska-Demel A, Chwiłkowska A, et al. An estimation of the biological properties of fish collagen in an experimental in vitro study. Adv Clin Exp Med. 2015; 24(3):385-392.

[33] Liu W, Tian Z, Li C, et al. Thermal denaturation of fish collagen in solution: a calorimetric and kinetic analysis. Thermochim Acta. 2014;581:32-40.

[34] Fernandes RMT, Couto Neto RG, Paschoal CWA, et al. Collagen films from swim bladders: preparation method and properties. Colloids Surfaces B Biointerfaces. 2008;62(1): $17-21$.

[35] Badea E, Della Gatta G, Usacheva T. Effects of temperature and relative humidity on fibrillar collagen in parchment: a micro differential scanning calorimetry (micro DSC) study. Polym Degrad Stab. 2012;97(3):346-353.

[36] Sun L, Hou H, Li B, et al. Characterization of acid- and pepsin-soluble collagen extracted from the skin of Nile tilapia (Oreochromis niloticus). Int J Biol Macromol. 2017;99:8-14.

[37] Yang H, Wang $\mathrm{H}$, Zhao $\mathrm{Y}$, et al. Effect of heat treatment on the enzymatic stability of grass carp skin collagen and its ability to form fibrils in vitro. J Sci Food Agric. 2015; 95(2):329-336.

[38] Zhang F, Wang A, Li Z, et al. Preparation and characterisation of collagen from freshwater fish scales. FNS. 2011;02:818-823.

[39] Zhang Y, Liu W, Li G, et al. Isolation and partial characterization of pepsin-soluble collagen from the skin of grass carp (Ctenopharyngodon idella). Food Chem. 2007;103(3): 906-912.

[40] Castignolles P, Gaborieau M. Viscosimetric detection in size-exclusion chromatography (SEC/GPC): the Goldwasser method and beyond. J Sep Science. 2010;33(22):3564-3570.

[41] Feng YC, Zhao H, Hao TH, et al. Effects of poly(cyclohexanedimethylene terephthalate) on microstructures, crystallization behavior and properties of the poly(ester ether) elastomers. Materials (Basel). 2017;10(7):694.

[42] Addad S, Exposito JY, Faye C, et al. Isolation, characterization and biological evaluation of jellyfish collagen for use in biomedical applications. Mar Drugs. 2011;9(6):967-983.

[43] Safari A, Cervantes MJ, Emami N. Viscoelastic behaviour effect of hyaluronic acid on reciprocating flow inside mini-channel. Lubr Sci. 2016;28(8):521-544.

[44] Pisárčik M, Bakoš D, Čeppan M. Non-Newtonian properties of hyaluronic acid aqueous solution. Colloids Surfaces A Physicochem Eng Asp. 1995;97(3):197-202. 